\title{
MOBILIDADE ESTUDANTIL NA AMÉRICA LATINA: REVELAÇÕES DA VALIDAÇÃO DE TÍTULOS ESTRANGEIROS NO BRASIL
}

\author{
MOVILIDAD ESTUDIANTIL EN AMÉRICA LATINA: REVELACIONES DE \\ VALIDACIÓN DE DIPLOMAS EXTRANJEROS EN BRASIL
}

\author{
STUDENT MOBILITY IN LATIN AMERICA: REVEALS OF VALIDATION OF \\ FOREIGN CERTIFICATES IN BRAZIL
}

\author{
Jullie Cristhie da CONCEIÇÃO ${ }^{1}$ \\ Milene Dias AMORIM ${ }^{2}$ \\ Giselle Cristina Martins REAL ${ }^{3}$
}

RESUMO: Objetiva-se mapear possíveis efeitos da Plataforma Carolina Bori no contexto dos processos de validação de cursos, de forma a compreender o movimento que essa política delineia, revelando a demanda, os destinos e os atores que permeiam tais processos. Para tanto, adotou-se análise dos dados públicos e restritos da Plataforma Carolina Bori. Foi possível observar que a Plataforma Carolina Bori, enquanto uma medida pública, ainda não foi capaz de produzir efeitos no movimento de mobilização estudantil no Brasil. Esse movimento continua caracterizado pela saída de brasileiros para cursos de graduação e de pós-graduação, em sua grande maioria, em países de língua latina, como Paraguai, Bolívia, Portugal, Espanha, o que não atende a perspectiva da política de internacionalização brasileira.

PALAVRAS-CHAVE: Revalidação de diplomas. Reconhecimento de títulos. Política Educacional. Educação Superior. Avaliação de Política.

RESUMEN: El objetivo es mapear los posibles efectos de la Plataforma Carolina Bori en el contexto de los procesos de validación del curso, a fin de comprender el movimiento que esta política describe, revelando la demanda, los destinos y los actores que impregnan dichos procesos. Con este fin, se adoptó un análisis de datos públicos y restringidos de la Plataforma Carolina Bori. Se pudo observar que la Plataforma Carolina Bori, como medida pública, aún no ha podido producir efectos en el movimiento de movilización de estudiantes en Brasil. Este movimiento continúa caracterizándose por la partida de brasileños para cursos de pregrado y posgrado, principalmente en países de habla latina, como Paraguay, Bolivia, Portugal, España, que no cumple con la perspectiva de la política de internacionalización brasileña.

${ }^{1}$ Universidade Federal da Grande Dourados (UFGD), Dourados - MS - Brasil. Doutoranda em Educação no Programa de Pós-graduação em Educação. ORCID: https://orcid.org/0000-0003-4026-4214. E-mail: jullie_cristhie@hotmail.com

${ }^{2}$ Universidade Federal da Grande Dourados (UFGD), Dourados - MS - Brasil. Doutoranda em Educação no Programa de Pós-graduação em Educação. ORCID: https://orcid.org/0000-0002-5292-1173. E-mail: mileneamorim@gmail.com

${ }^{3}$ Universidade Federal da Grande Dourados (UFGD), Dourados - MS - Brasil. Professora Associada III do Programa de Pós-Graduação em Educação. Doutorado em Educação (USP). ORCID: https://orcid.org/00000002-8855-4141. E-mail: gisellereal@ufgd.edu.br 
PALABRAS CLAVE: Revalidación de diplomas. Reconocimiento de títulos. Política educativa. Educación superior. Evaluación de políticas.

ABSTRACT: The objective is to map the possible effects of the Carolina Bori Platform in the context of the course validation processes, in order to understand the movement that this policy outlines, revealing the demand, destinations and actors that permeate these processes. To this end, an analysis of the public and restricted data of the Carolina Bori Platform was adopted. It was possible to observe that the Carolina Bori Platform, as a public measure, has not yet been able to produce effects on the student mobilization movement in Brazil. This movement continues to be characterized by the departure of Brazilians for undergraduate and graduate courses, mostly in Latin-speaking countries such as Paraguay, Bolivia, Portugal, Spain, which does not meet the perspective of the Brazilian internationalization policy.

KEYWORDS: Revalidation of diplomas. Title recognition. Educational politics. Higher education. Policy Evaluation.

\section{Introdução}

O Executivo brasileiro implementou, em 2016, um sistema informacional ${ }^{4}$ próprio para proceder a reconhecimentos e revalidações de diplomas estrangeiros, identificado como Plataforma Carolina Bori. Esta plataforma foi instituída pela Portaria Normativa $\mathrm{n}^{\circ} 22$, de 13 de dezembro de 2016, do Ministério da Educação (MEC), com base na Lei no 9.394, de 20 de dezembro de 1996 (BRASIL, 1996), e na Resolução do Conselho Nacional de Educação/Câmara de Educação Superior (CNE/CS) no 3, de 22 de junho de 2016 (MEC, 2016).

A proposição de criação de um sistema informacional para disciplinar a demanda crescente de revalidação e de reconhecimento de títulos estrangeiros também teve a chancela do Legislativo brasileiro, no contexto das discussões do Projeto de Lei (PL) n 399/2011, posteriormente convertido no PL n $\mathrm{n}^{\mathrm{0}} 7841 / 2014$, que propõe a revalidação automática de títulos, atualmente revalidação simplificada (REAL; MARRAN; ZENI, 2019).

$\mathrm{O}$ crescimento de processos de validação ${ }^{5}$ de diplomas estrangeiros no Brasil torna-se crescente a partir de meados da década de 1990, quando o sistema educacional não consegue atender, no setor público, o número de brasileiros que buscam acesso à educação superior

${ }^{4}$ Disponível em: http://carolinabori.mec.gov.br. Acesso em: 26 mar. 2020.

${ }^{5}$ A opção do uso do termo "validação" é por aglutinar o significado tanto do conceito de revalidação, específico para cursos de graduação, quanto do de reconhecimento, próprio para curso de pós-graduação stricto sensu, conforme disciplinado no art. 48 da LDB (BRASIL, 1996). 
(GISI; PEGORINI, 2016), sobretudo em cursos de medicina. Nesse contexto, é desencadeado um movimento crescente de brasileiros para cursos em instituições estrangeiras, em sua grande maioria privadas, vinculadas a países fronteiriços, que ofertam cursos com mensalidades mais compatíveis do que as operadas no contexto local, considerando a valorização do real frente à moeda desses países, bem como a ausência de processos seletivos de entrada, os chamados vestibulares (CONCEIÇÃO, 2013; ALVARES; REAL, 2014).

Até então os pedidos de revalidação e reconhecimento de títulos estrangeiros ocorriam, sobretudo, por pessoas estrangeiras que pretendiam exercer a profissão no Brasil, o que requeria a regularização do título (SANTOS; REAL, 2020).

O aumento dos fluxos de saída e de retorno de brasileiros em virtude de titulação estrangeira constitui-se como problemática a compor a agenda do Estado brasileiro, considerando suas influências na elaboração de políticas regionais junto aos Estados membros do Mercosul e no número de ações judiciais que chegam ao Supremo Tribunal Federal (REAL; MARRAN; ZENI, 2019; REAL; COSTA, 2019).

Nesse sentido, a partir de 2002, o Executivo brasileiro busca equacionar a questão por meio da adoção de medidas em duas direções: i) a normatização do processo por meio de resoluções do Conselho Nacional de Educação, direcionando as universidades e instituições na condução desse processo ${ }^{6}$; ii) criação, em 2010, do Projeto Piloto do Exame Nacional de Revalidação de Diplomas Médicos (Revalida), institucionalizado em 2011 e vigente até o presente momento ${ }^{7}$.

Essas iniciativas, por sua vez, implicaram em um número reduzido de pedidos deferidos, o que provocou embates entre associações de estudantes ${ }^{8}$, órgãos governamentais ${ }^{9}$ e entidades de classes, como é o caso do Conselho Federal de Medicina (CONCEIÇÃO, 2013). Os embates tinham como questão subjacente ao processo de validação de títulos a qualidade da formação desenvolvida nos países fronteiriços (REAL; MARRAN; ZENI, 2017).

\footnotetext{
${ }^{6} \mathrm{O}$ art. 48 de LDB estabelece autonomia para que as universidades públicas procedam ao processo de revalidação de diplomas de graduação e às instituições que tenham cursos equivalentes reconhecidos para proceder ao reconhecimento de mestrados e doutorados.

${ }^{7}$ Nesse sentido, ver Lei n. 13.959, de 18 de dezembro de 2019 que institui o Exame Nacional de Revalidação de Diplomas Médicos Expedidos por Instituição de Educação Superior Estrangeira (Revalida) (BRASIL, 2019).

${ }^{8}$ São exemplos dessas instituições a Associação Brasileira de Pós-Graduados no Mercosul (ABPÓS-Mercosul). Associação de Medicina no Exterior (Ameex); Associação Nacional de Pós-Graduados em Instituições Estrangeiras (ANPGIEES).

${ }^{9}$ Nesse sentido ver notas da Coordenação de Aperfeiçoamento de Pessoal de Ensino Superior (CAPES): Capes (2005); Guimarães (2011).
} 
Com a criação da Plataforma Carolina Bori, em um período superior a vinte anos das primeiras medidas normativas adotadas pelo Executivo brasileiro, incita-se questões como: que alterações ocorreram no movimento de estudantes brasileiros por instituições estrangeiras, após a implementação da Plataforma Carolina Bori? Quais as origens dos diplomas que requerem validação? Quais as características dos pedidos de validação de títulos no Brasil? Há diferenças nos processos de reconhecimento e de revalidação de cursos?

Diante desse cenário, o presente artigo, sem pretensões de responder ao conjunto de todas essas questões, mas intencionando contribuir com as políticas em curso, tem como objetivo: mapear possíveis efeitos, especialmente configurados após a institucionalização da Plataforma Carolina Bori, no contexto dos processos de validação de cursos, de forma a compreender o movimento que essa política delineia, revelando não apenas a demanda por validação, mas também destinos e atores que permeiam tais processos.

Para o atendimento desse objetivo, foi realizada pesquisa documental junto ao Portal eletrônico da Plataforma Carolina Bori, para coleta de dados abertos, e posteriormente, foi solicitado acesso a dados não publicados. Esses dados restritos foram encaminhados pela Secretaria de Educação Superior, por meio de solicitação realizada ao Ministério da Educação (MEC), a partir do Sistema Eletrônico do Serviço de Informação ao Cidadão (e-SIC) ${ }^{10}$, em 15 de outubro de 2019, tendo obtido a resposta em 18 de novembro de 2019 (MEC, 2019).

$\mathrm{O}$ artigo está dividido em duas seções, além das considerações finais. A primeira seção vai tratar da revalidação, que se refere à validação de títulos de graduação, e a segunda seção abarca o reconhecimento de títulos, que consiste na chancela dos diplomas de pós-graduação stricto sensu.

\section{Revalidação de diplomas de graduação estrangeiros no brasil}

A Plataforma Carolina Bori foi disponibilizada aos Reitores através de um convite eletrônico às Universidades públicas e privadas, para adesão facultativa.

A justificativa apresentada pelo MEC para a criação dessa plataforma incidiu em aspectos procedimentais dos processos de revalidação e de reconhecimento, como a letargia das instituições no andamento dos pedidos (MEC, 2020a).

A maioria das instituições fez a adesão completa, ou seja, para os dois processos, tanto de revalidação de cursos de graduação quanto para o reconhecimento de pós-graduação stricto sensu. Segundo os dados constantes na Plataforma Carolina Bori, 66 instituições contemplam

${ }^{10}$ Disponível em: https://esic.cgu.gov.br/sistema/site/index.aspx. Acesso em: 26 mar. 2020. 
os dois processos, 04 aderiram apenas à revalidação e 37 aderiram apenas ao reconhecimento, o que perfaz um total de 107 Instituições, sendo 70 instituições para processos de revalidação e 103 para processos de reconhecimento de cursos.

Esses dados permitem notar que há mais instituições credenciadas para o reconhecimento de cursos, uma vez que estas representam 96,26\% do total, e as instituições credenciadas para a revalidação se configuram em $65,42 \%$ do conjunto das instituições que aderiram ao sistema. Esses dados podem ser justificados considerando que há uma preponderância de pedidos de revalidação para cursos na área de medicina, onde se observa resistências por parte da classe médica (CONCEIÇÃO, 2013), o que poderia limitar a adesão de parte das instituições para essa finalidade.

No entanto, pode-se inferir que apesar das resistências a adesão para o ato de revalidação de diplomas foi significativa, tendo em vista o número de Instituição de Ensino Superior (IES) cadastradas em 2017 e o aumento efetivado nos anos seguintes, que implicou incremento em torno de $22,86 \%$ em menos de 3 anos, conforme pode ser observado no Quadro 01.

Quadro 01 - Instituição de Ensino Superior que aderiram à Plataforma Carolina Bori para a revalidação de cursos, no período de 2017 a 2020

\begin{tabular}{|c|c|c|c|c|c|}
\hline Região & $\mathbf{2 0 1 7}$ & $\mathbf{2 0 1 8}$ & $\mathbf{2 0 1 9}$ & $\mathbf{2 0 2 0}^{*}$ & Total \\
\hline Centro-Oeste & 06 & 01 & 01 & - & 08 \\
\hline Norte & 08 & 01 & 01 & - & 10 \\
\hline Nordeste & 11 & 05 & 01 & - & 17 \\
\hline Sul & 12 & 01 & 01 & - & 14 \\
\hline Sudeste & 15 & 04 & - & 02 & 21 \\
\hline Total & 52 & 12 & 04 & - & 70 \\
\hline
\end{tabular}

Fonte: Elaboração própria com base nos dados disponíveis na Plataforma Carolina Bori (BRASIL, 2020)

Salienta-se que das 70 instituições que estão credenciadas na Plataforma para a revalidação, 50 são universidades federais, 17 estaduais, 02 municipais e 01 privada ${ }^{11}$, estando a localização geográfica das instituições assim distribuída: região sudeste com maior número, sendo $30 \%$ do total, seguida pela região nordeste com $24,29 \%$; a Região Sul com 20\%; a Região Norte $14,29 \%$ e com menor número de instituições a região Centro-Oeste com $11,43 \%$ do total. Os dados revelam que há distribuição equitativa, considerando o número de instituições de educação superior existente nas respectivas regiões.

\footnotetext{
${ }^{11}$ No caso da adesão da instituição privada acredita-se que deva ter ocorrido erro no preenchimento dos dados
} cadastrais, pois o art. 48 de LDB restringe a revalidação de diplomas de graduação às instituições públicas. 
O Quadro 02, a seguir exposto, traz os dados referentes à nacionalidade dos candidatos.

Quadro 02 - Nacionalidade, por continente, dos requerentes de revalidação de cursos, junto à Plataforma Carolina Bori, no período de 2017 a 2019

\begin{tabular}{|c|c|c|}
\hline Continente & Países dos requerentes & Número de Requerentes \\
\hline América & 22 & 3574 \\
\hline Europa & 18 & 193 \\
\hline Ásia & 13 & 73 \\
\hline África & 13 & 42 \\
\hline Oceania & - & - \\
\hline Total & 66 & 3882 \\
\hline
\end{tabular}

Fonte: Elaboração própria com base nos dados disponibilizados pelo MEC (MEC, 2019)

No que se refere ao número de candidatos por continente, nota-se que $92,07 \%$ tem origem no continente americano, explicitando haver uma concentração geográfica. Ainda, cumpre destacar que a grande maioria são de brasileiros, que somam um total de 2.586 requerentes, representando $66,6 \%$ do total de pedidos de revalidação no período considerado. Além de brasileiros, configuram como maiores requerentes: colombianos, que somam 214 pedidos; venezuelanos, que são 151; bolivianos, com 142 pedidos; peruanos, com 122 requerimentos e, ainda, cubanos, que somam 99 solicitações. Desse modo, com números menos expressivos apresentam-se os demais continentes, que ao todo totalizam 7,93\%.

Destaca-se ainda que dos países pertencentes ao continente americano a maioria é de nacionalidade latino-americana, com 3.554 solicitações, ou seja, 91,5\% do total de pedidos de revalidação. Mais especificamente, são 3.237 requerentes com nacionalidade de países membros e associados ao Mercosul ${ }^{12}$, o que perfaz $83,3 \%$ da nacionalidade dos candidatos.

O mesmo pode ser observado sobre a origem dos diplomas, como mostra o Quadro 03.

Quadro 03 - IES de origem dos diplomas estrangeiros de graduação, por continente, na Plataforma Carolina Bori, no período de 2017 a 2019

\begin{tabular}{|c|c|c|}
\hline Continente & Número de Países & Número de requerentes \\
\hline América & 22 & 3145 \\
\hline Europa & 24 & 576 \\
\hline Ásia & 19 & 99 \\
\hline África & 14 & 53 \\
\hline Oceania & 1 & 9 \\
\hline Total & 80 & 3882 \\
\hline
\end{tabular}

Fonte: Elaboração própria com base nos dados disponibilizados pelo MEC (MEC, 2019)

12 Nesse montante não foram considerados os requerentes da Venezuela, por estar suspensa do bloco, desde 2016. 
Nota-se que todos os continentes possuem diplomas de graduação com requerimento para revalidação. Apesar do continente europeu apresentar maior número de países, é o continente americano que concentra a grande maioria do número de requerentes com diploma, o que representa $81,01 \%$ do total, sendo a Bolívia a origem do maior número de diplomas, com 1.308. Os países que mais originam os diplomas depois da Bolívia são: Paraguai, com 379; Estados Unidos, com 278; Colômbia, com 239; Venezuela, com 232; Cuba, com 183; Argentina, com 168 e, ainda, Peru, com 152. Os diplomas originados em países da Europa correspondem a 14,84\%, sendo o destaque de 147 diplomas de Portugal; 97 da Espanha; 75 da França; 66 da Itália; e 60 do Reino Unido. Os demais continentes representam 4,15\% do total.

No que se refere a diplomas com origem da América Latina, é possível perceber que 2.842, ou seja, 73\% diplomas, foram obtidos em países latino-americanos, sendo de países que compõem o Mercosul um total de 2.350 pedidos, o que representa $60,5 \%$ dos diplomas de graduação proveniente de 08 países vinculados ao Mercosul.

Em relação à modalidade de tramitação dos processos, previstos na Resolução CNE/CES no 3/2016 (MEC, 2016), pode-se destacar que concentram os processos na modalidade "normal", sendo que a tramitação simplificada tem 09 pedidos. Os pedidos em trâmite simplificado são: 06 diplomas de cursos acreditados no Sistema Arcu-Sul; 02 diplomas obtidos por meio do Módulo Internacional do Prouni; 01 diploma de cursos que receberam bolsistas brasileiros de agências governamentais.

Tais constatações evidenciam que o movimento delineado pela política de revalidação permanece caracterizado pela saída de brasileiros para realizarem seus cursos no âmbito dos países fronteiriços, sobretudo medicina, com intencionalidade de retornar para o exercício profissional no âmbito local, constituindo-se em um efeito bumerangue, conforme descrito pela literatura da área para processos anteriores à criação da Plataforma Carolina Bori (CONCEIÇÃO, 2013; ALVAREZ; REAL, 2014).

No entanto, há que se destacar que o delineamento particularizado pela Plataforma Carolina Bori passa a apresentar alguns pontos fora da linha contínua que o caracterizava. Pode-se observar que há uma maior pulverização da origem dos diplomas, inclusive com incidência na Europa, ainda que em percentuais menores, uma vez que representa $14,84 \%$ do total dos processos de revalidação em curso, embora o foco tenha ocorrida em Portugal e na Espanha, países que têm proximidade com a língua. Também pode-se observar que há ampliação da origem dos requerentes à revalidação, que sinaliza, ainda que de forma tímida, a presença de estrangeiros solicitando revalidação de seus títulos para atuar no Brasil, ainda 
com maior quantidade de latino-americanos como: colombianos, venezuelanos, bolivianos, peruanos e cubanos.

\section{O processo de reconhecimento de diplomas de pós-graduação estrangeiros}

Assim como acontece com a busca pela graduação estrangeira, a pós-graduação (PG) também desenvolveu movimento crescente por titulação no exterior (REAL; COSTA, 2019; VILARINHO; GONZALEZ, 2014).

Há um consenso na literatura que as mudanças sociais, econômicas e tecnológicas acarretadas pela ótica neoliberal provocam transformações nos cenários nacional e internacional e têm causado um aumento progressivo da demanda por maior formação dentro da educação superior (DELGADO; PESSOA, 2010). Tal aumento é acompanhado por novas exigências formativas dentro da PG também (CUNHA; CRUZ; BIZELLI, 2017; ROBERTSON, 2009; DIAS SOBRINHO, 2005).

Diante das grandes exigências de formação impulsionadas pela globalização e da falta de vagas públicas para cobrir a demanda, tem se configurado como uma crescente a busca de brasileiros por cursos de mestrado e doutorado em outros países, especialmente localizados em regiões de fronteira, como o Paraguai. A maioria destes possui por intenção retornar ao Brasil para a atuação profissional, o que implica em pedidos de reconhecimento desses diplomas (REAL; COSTA, 2019; VILARINHO; GONZALEZ, 2014).

Assim, o processo prescrito na Lei n. 9.394/1996 (BRASIL, 1996), que prevê a autonomia das IES, deixa de ser suficiente, promovendo ações do Estado brasileiro nessa direção a partir de 2002 (CONCEIÇÃO, 2013), como é o caso, entre outras medidas normativas, da criação da Plataforma Carolina Bori.

Os dados informados na plataforma (MEC, 2019) somam um quantitativo de 5.831 processos de solicitação. Destes, 3.670 requerimentos são de diplomas de mestrado e 2.161 são de doutorado. Das instituições credenciadas, 36 universidades federais, 25 privadas e 11 estaduais foram procuradas para realização de reconhecimento, o que perfaz um total de 72 instituições (MEC, 2020b). Esse dado sinaliza que, das instituições credenciadas junto à Plataforma Carolina Bori, 70,59\% tiveram pedidos de reconhecimento de cursos, explicitando o seu potencial em atingir amplitude na abrangência geográfica e na diversificação na forma de organização administrativa das IES, uma vez que não se identifica foco de interesse dos candidatos a determinadas instituições ou regiões do país. Pode-se notar que as universidades federais são responsáveis por $78 \%$ dos pedidos, as universidades estaduais são procuradas por 
$5,2 \%$ dos interessados e $16 \%$ dos pedidos são creditados nas universidades privadas (MEC, 2019).

Cabe salientar que não são apenas brasileiros que pedem esse reconhecimento, embora seja a grande maioria. Os números contabilizam 5.579 pedidos feitos por brasileiros e 252 pedidos feitos por estrangeiros do mundo todo (MEC, 2019). Portanto, os brasileiros representam $95,68 \%$ dos pedidos de reconhecimento de diplomas estrangeiros.

Os profissionais de origem cubana são, fora os brasileiros, os que mais solicitaram reconhecimento de diplomas de PG no país, com 37 pedidos durante o período analisado, o que representa $0,63 \%$ do conjunto dos pedidos de reconhecimento de títulos.

Ao todo são 38 nacionalidades solicitantes, o que expõe limite de abrangência geográfica na origem dos candidatos.

No quadro abaixo, verifica-se por continente esses números:

Quadro 04 - Quantitativo de solicitantes de reconhecimento de diplomas no Brasil por continente, no período de 2017 a 2019

\begin{tabular}{|c|c|c|c|}
\hline \multicolumn{5}{|c|}{ Origem do solicitante } \\
\hline Continente & Quant. países & Quant. solicitantes & $\%$ \\
\hline América & 14 & 5.692 & 97,62 \\
\hline Europa & 13 & 108 & 1,85 \\
\hline Ásia & 05 & 20 & 0,34 \\
\hline África & 05 & 10 & 0,17 \\
\hline Oceania & 01 & 01 & 0,02 \\
\hline Total & 38 & 5831 & 100 \\
\hline
\end{tabular}

Fonte: elaboração própria a partir de dados da plataforma Carolina Bori (MEC, 2019)

Esses dados indicam um movimento em efeito bumerangue, ou seja, os brasileiros saem para cursar mestrado e doutorado fora do país e retornam para desenvolver suas atividades profissionais. Por outro lado, a atratividade de estrangeiros para o Brasil tem sido em escala significativamente menor, com destaque para a presença de cubanos.

No que diz respeito à nacionalidade dos diplomas de pós-graduação dos solicitantes, tem-se um cenário diferente da situação dos diplomas de graduação. Enquanto a procedência dos diplomas de graduação está, em grande parte, no seio da América Latina e com maior força dentro dos países do Mercosul, a procedência dos diplomas de PG tem a maior concentração na origem europeia, conforme consta no quadro a seguir. 
Quadro 05 - Origem de diplomas estrangeiros, por continente, para reconhecimento de cursos, na Plataforma Carolina Bori, no período de 2017 a 2019

\begin{tabular}{|c|c|c|}
\hline \multicolumn{3}{|c|}{ Origem do diploma } \\
\hline América & Quant. países & Quant. diplomas \\
\hline Europa & 15 & 1.649 \\
\hline Ásia & 22 & 3.369 \\
\hline África & 11 & 43 \\
\hline Oceania & 05 & 09 \\
\hline
\end{tabular}

Fonte: elaboração própria a partir de dados da plataforma Carolina Bori (MEC, 2019)

De acordo com os dados, 57\% dos diplomas de PG que chegam ao Brasil para serem reconhecidos são europeus, sendo que os cinco países que aparecem em maior quantidade são Portugal, com 1.912 diplomas; Espanha, com 487; Reino Unido, com 285; França, com 249; e Alemanha, com 135 diplomas. Este cenário pode ser uma consequência do Acordo de Bolonha. Segundo Robertson (1999), o Espaço Europeu de Educação Superior, constituído no contexto do Acordo de Bolonha, intentou imprimir atratividade de estudantes para a Europa, que vinha perdendo espaços comerciais para países como os Estados Unidos. Outro fator a ser considerado para a concentração de titulação em Portugal e Espanha seria a proximidade com o idioma (VARGHESE, 2008).

A América está na sequência, com $40 \%$ dos diplomas solicitantes de reconhecimento. O Paraguai lidera esta estatística com 1.124 diplomas, sendo o segundo país com maior concentração dos títulos estrangeiros, depois de Portugal. Ainda, no continente americano, há títulos oriundos dos Estados Unidos, com 521 pedidos; da Argentina, com 346; de Porto Rico, com 72; e do Chile, com 67 diplomas. Cuba aparece em $8^{\circ}$ lugar, com 39 pedidos, o que é bastante compatível com o número dos próprios cubanos requerentes, que perfazem 37 pedidos.

A grande presença de diplomas paraguaios, argentinos e chilenos na lista de solicitantes pode ser justificada pelo fato destes participarem, juntamente com o Brasil, do Acordo do Mercosul. Há uma crença errônea de que, devido ao acordo entre estes, seus diplomas serão facilmente, ou até diretamente, reconhecidos no Brasil; no entanto, Coimbra e Faria (2016) afirmam que não existe, na legislação brasileira, regra que embase e viabilize o reconhecimento automático de títulos educacionais pelo fato destes serem adquiridos nos países partícipes. A Plataforma Carolina Bori aparece como a primeira iniciativa do Estado brasileiro a viabilizar o chamado procedimento simplificado para esses casos, conforme descrito na Resolução CNE/CS nº 3/2016 (CNE, 2016). 
Cabe destacar, nesse aspecto, um novo delineamento para o movimento deflagrado por Vinharinho e Gonzalez (2014), que indicava o Paraguai como foco na origem dos títulos, enquanto que atualmente é Portugal o destino mais procurado pelos brasileiros, abrindo espaços para dois eixos de concentração de títulos: Paraguai e Argentina em um polo formador e Portugal e Espanha em outro polo. O percentual da origem dos títulos se concentrar em Portugal e Espanha é significativo, pois juntos detêm 41,14\% dos títulos, enquanto Paraguai e Argentina são responsáveis por $25,21 \%$ da origem dos títulos que demandam reconhecimento.

Mesmo assim, o trânsito entre estes países é grande para tal finalidade. Alvares e Real (2014) afirmam que a preferência dos brasileiros se explica pelo cunho econômico, fenômeno que pode ser identificado como "cross border education" (KNIGHT, 2006), pois as instituições acolhedoras nesses países em geral não possuem notório reconhecimento acadêmico, que pudesse creditar tamanho movimento migratório. Também pode-se citar como motivação para a escolha desses países algumas facilidades existentes, como a ausência de vestibular ou qualquer outro processo seletivo; o acesso geográfico, por serem fronteiras secas; e a moeda brasileira, que possui valorização maior nestes, acarretando no barateamento dos cursos nas instituições acolhedoras, uma vez que são todas privadas.

Os países tradicionalmente referenciados para a qualificação de pós-graduação, na conhecida mobilidade sul-norte (MOROSINI, 2006), como Estados Unidos, Reino Unido, França, Alemanha, representam juntos $20,40 \%$ da origem dos títulos.

Em relação à tramitação dos processos de reconhecimento de cursos, a Resolução $\mathrm{CNE} / \mathrm{CS} \mathrm{n}^{\mathrm{o}}$ 3/2016 (MEC, 2016) prevê, em seu art. 20 e seguintes, o procedimento simplificado quando se tratar de diplomas que já tenham sido objeto de reconhecimento anterior, considerando um prazo de 10 anos, ou ser fruto de convênios os programas de agências governamentais como o Ciências sem Fronteira, bolsas concedias pela Capes e CNPq.

Deve-se destacar que entre os solicitantes de reconhecimento de diplomas estrangeiros de mestrado e doutorado no Brasil, 48,6\% são mulheres e 51,2\% são homens; apenas duas pessoas não identificaram seu gênero, o que indica que as mulheres também estão avançando na busca por titulação no exterior, fato que explicita uma pequena alteração no perfil dos atores que compõem a pós-graduação brasileira.

Diante do exposto, verifica-se que, nos últimos anos, a procura por reconhecimento de diplomas de cursos de pós-graduação estrangeiros no Brasil tem se configurado como uma onda crescente e, embora haja uma determinada diversificação na origem dos requerentes ao 
reconhecimento de títulos, o número de brasileiros soma 95,6\% do total geral, o que revela que o reconhecimento de títulos se constitui como uma alternativa para que brasileiros busquem realizar sua pós-graduação no exterior, especialmente adotando como escolha para sua formação países de língua latina, notadamente Portugal e Paraguai, que não se constituem como centros internacionais tradicionais de formação de profissionais de alta qualificação.

\section{Considerações finais}

Ao analisar os dados disponibilizados sobre os processos de revalidação e reconhecimento de títulos estrangeiros que estão tramitando no período de 2017 a 2019 na Plataforma Carolina Bori, que se constitui como uma medida recente do Estado brasileiro, foi possível identificar o movimento de mobilização que está implícito a esse processo.

Nesse sentido, foi possível notar que a Plataforma Carolina Bori, enquanto uma medida pública, ainda não foi capaz de produzir efeitos no movimento de mobilização estudantil no Brasil. Esse movimento continua caracterizado pela saída de brasileiros para cursos de graduação e de pós-graduação que se concentram em instituições localizadas em países de região de fronteira.

Ainda que esse movimento tenha nuances de ampliação da nacionalidade dos atores, indicando a presença de latino-americanos buscando atuação profissional no Brasil, e da origem dos títulos que passam a envolver também países da Europa, particularmente concentrados em Portugal e Espanha, a perspectiva que se projeta ainda indica por matiz mais forte em torno de interesses particulares de cada ator na busca de sua projeção profissional, atrelados a interesses de ordem comercial de instituições privadas. Tais instituições estrangeiras diante do cenário globalizado e de cunho neoliberal constroem políticas institucionais de atratividade de brasileiros, que não apresentam condições de acessar cursos de graduação de carreiras supervalorizadas pelo mercado profissional e de pós-graduação públicas.

Apesar das normas brasileiras apontarem por processos de revalidação e de reconhecimento simplificado para casos de diplomas originados em instituições que já passaram por processos avaliativos anteriores, considerando os últimos dez anos, ou vinculados a programas engendrados em decorrência de acordos de cooperação internacional e/ou já acreditados, esses se constituem por percentual insignificante diante dos números existentes, o que revela que a mobilização estudantil envolvendo brasileiros insere-se no 
contexto de movimento identificado como "cross border education", considerando os interesses comerciais implícitos e não como iniciativa de política de internacionalização.

Embora tenham sido observadas pequenas diferenciações na mobilização de estudantes que requerem revalidação dos títulos de graduação daqueles que requerem reconhecimento de cursos de pós-graduação stricto sensu, as particularidades dos processos os aproximam com mais intensidade. Portanto, apesar dos percentuais da PG apresentarem incidência maior para Portugal, no continente Europeu, enquanto a graduação mantém a preponderância de títulos originados na Bolívia, no continente americano, ambos não apresentam mobilidade apoiada em acordos de cooperação, nem mesmo na política de internacionalização brasileira.

A política de internacionalização brasileira intenciona movimentos de mobilização que envolvam a direção sul-norte, especialmente junto a instituições localizadas em países que lideram o desenvolvimento científico e industrial mundial.

Diante desse cenário prospectivo espera-se que esse artigo possa contribuir com indicativos para se avaliar as políticas nacionais para a área.

\section{REFERENCIAS}

ALVARES, A. de L. T. REAL, G. C. M. Educação superior: o processo de mobilidade nas faixas de fronteira. In: ENCUENTRO INTERNACIONAL DE EDUCACIÓN, 1., 2014, Argentina. Anais [...]. Argentina: Facultad de Ciencias Humanas - UNCPBA, out. 2014.

BRASIL. Lei n. 9.304, de 20 de dezembro de 1996. Estabelece as diretrizes e bases da educação nacional. Brasília: Palácio do Planalto, 1996. Disponível em: http://www.planalto.gov.br/ccivil_03/leis/19394.htm. Acesso em: 07 mar. 2010.

BRASIL. Lei n. 13.959, de 18 de dezembro de 2019. Institui o Exame Nacional de Revalidação de Diplomas Médicos Expedidos por Instituição de Educação Superior Estrangeira (Revalida). Brasília: Palácio do Planalto, 2019. Disponível em: http://www.planalto.gov.br/ccivil_03/_ato2019-2022/2019/lei/L13959.htm. Acesso em: 10 abr. 2020.

CAPES. Nota à imprensa - Reconhecimento de títulos de pós-graduação obtidos no exterior. Brasília: Capes, 2005. Disponível em: http://www.capes.gov.br/36-noticias/1164-nota-aimprensa-reconhecimento-de-titulos-de-pos-graduacao-obtidos-no-exterior. Acesso em: 05 abr. 2020.

COIMBRA, R.; FARIA, T. S. Reflexões sobre a revalidação dos diplomas acadêmicos do MERCOSUL no Brasil. RJLB, Ano 2, n. 4, 2016. ISSN 1499-1521.

CONCEIÇÃO, J. C. da. A expansão da educação superior e os efeitos no processo de revalidação de títulos de graduação em Mato Grosso do Sul. 2013. 156 f. Dissertação 
(Mestrado em Educação) - Universidade Federal da Grande Dourados, Dourados, 2013. Disponível em: http://files.ufgd.edu.br/arquivos/arquivos/78/MESTRADO-DOUTORADOEDUCACAO/JULLIE\%20CRISTHIE\%20DA\%20CONCEI\%C3\%87\%C3\%83O.pdf. Acesso em: 15 abr. 2020.

CUNHA, A. K.; SANTOS CRUZ, J. A.; BIZELLI, J. L. A gestão do conhecimento e as expertises desenvolvidas no ensino superior. Revista on line de Política e Gestão Educacional, Araraquara, v. 21, n. esp. 1, p. 677-690, out. 2017. e-ISSN: 1519-9029. Disponível em: https://periodicos.fclar.unesp.br/rpge/article/view/10442/6803. Acesso em: 13 mar. 2020.

DELGADO, D. M.; PESSOA, M. B. D. A educação superior no contexto da inovação como fator estratégico no setor produtivo: um estudo empírico aplicado a cenários regionais.

Revista on line de Política e Gestão Educacional, Araraquara, n. 8, 2010. e-ISSN: 15199029. Disponível em: https://periodicos.fclar.unesp.br/rpge/article/view/9262. Acesso em: 26 mar. 2020.

DIAS SOBRINHO, J. Educação superior, globalização e democratização: qual universidade? Revista Brasileira de Educação, Rio de Janeiro, n. 28, jan. /fev. /mar. /abr. 2005.

GISI, M.L.; PEGORINI, D.G. As políticas de acesso e permanência na educação superior: a busca da igualdade de resultados. Revista on line de Política e Gestão Educacional, Araraquara, v. 20, n. 1, jan./abr. 2016. e-ISSN: 1519-9029. Disponível em: https://periodicos.fclar.unesp.br/rpge/article/view/9390. Acesso em: 21 mar. 2020.

GUIMARÃES, J. A. Nota da Capes sobre reconhecimento de títulos de pós-graduação obtidos em instituições do exterior. Brasília: Capes, 2011. Disponível em: http://www.capes.gov.br/acessoainformacao/informacoes-classificadas/72salaimprensa/destaques/4763-nota-da-capes-sobre-reconhecimento-de-titulos-de-posgraduacao-obtidos-em-instituicoes-do-exterior. Acesso em: 19 abr. 2020.

MARRAN, A. L; REAL, G.C.M.; ZENI, K. A política de revalidação de títulos estrangeiros: interfaces entre executivo, legislativo e judiciário. Revista Ibero-Americana de Estudos em Educação, Araraquara, v. 14, n. 3, p. 1-14, jul./set. 2019. Disponível em: https://periodicos.fclar.unesp.br/iberoamericana/article/view/11573/8143. Acesso em: 23 mar. 2020 .

MEC. Portal Carolina Bori: revalidação/reconhecimento de diplomas estrangeiros. Disponível em: http://carolinabori.mec.gov.br/. Acesso em: 08 mar. 2020a.

MEC. Portal Carolina Bori: instituições que aderiram a plataforma Carolina Bori. Disponível em: http://plataformacarolinabori.mec.gov.br/consulta-publica/adesao/consulta. Acesso em: 15 mar. 2020b.

MEC. Resolução n. 3, de 22 de junho de 2016. Dispõe sobre normas referentes à revalidação de diplomas de cursos de graduação e ao reconhecimento de diplomas de pós-graduação stricto sensu (mestrado e doutorado), expedidos por estabelecimentos estrangeiros de ensino superior. Diário Oficial da União, Brasília, Seção 1, p. 9-10, 23 jun. 2016. 
MEC. Informações dos processos em tramitação na Plataforma Carolina Bori. Destinatário: Milene Dias Amorim. [S. l.]. 18 nov. 2019. Mensagem eletrônica.

MOROSINI, M. C. Estado do conhecimento sobre internacionalização da educação superior Conceitos e práticas. Educar, Curitiba, n. 28, p. 107-124, 2006. Disponível em: https://www.scielo.br/pdf/er/n28/a08n28.pdf. Acesso em: 14 fev. 2020.

REAL, G. C. M.; COSTA, F. G. da. Reconhecer ou não reconhecer títulos estrangeiros? A questão posta aos tribunais brasileiros. Revista @mbienteeducação, São Paulo, v. 12, n. 3, p. 283 -298, set./dez. 2019. Disponível em:

http://publicacoes.unicid.edu.br/index.php/ambienteeducacao/article/view/775/707. Acesso em: 17 abr. 2010.

ROBERTSON, S. L. O processo de Bolonha da Europa torna-se global: modelo, mercado, mobilidade, força intelectual ou estratégia para construção do Estado? Revista Brasileira de Educação, Rio de Janeiro, v. 14, n. 42, p. 407-600, set./dez. 2009.

SANTOS, D. P. dos; REAL, G. C. M. Revalidação de diplomas estrangeiros no Brasil: destaques da literatura científica. Laplage em Revista, Sorocaba, v. 6, n. 2, p. 149-160, maio/ago. 2020. Disponível em:

http://www.laplageemrevista.ufscar.br/index.php/lpg/article/view/842/1046. Acesso: 4 maio 2020.

VARGHESE, N. V. Globalization of higher education and cross-border student mobility. Paris: International Institute for Education Planning, 2008.

\section{Como referenciar este artigo}

CONCEIÇÃO, J. C. da; AMORIM, M. D.; REAL, G. C. M. Mobilidade estudantil na América Latina: revelações da validação de títulos estrangeiros no Brasil. Revista on line de Política e Gestão Educacional, Araraquara, v. 24, n. esp. 1, p. 747-761, ago. 2020. eISSN:1519-9029. DOI: https://doi.org/10.22633/rpge.v24iesp1.13780

Submetido em: 20/02/2020

Revisões requeridas: $30 / 04 / 2020$

Aprovado em: 28/06/2020

Publicado em: 01/08/2020 